\title{
Effect of Illumination Angle on the Performance of Dusted Thermal Control Surfaces in a Simulated Lunar Environment
}

James R. Gaier

Glenn Research Center, Cleveland, Ohio 


\section{NASA STI Program . . . in Profile}

Since its founding, NASA has been dedicated to the advancement of aeronautics and space science. The NASA Scientific and Technical Information (STI) program plays a key part in helping NASA maintain this important role.

The NASA STI Program operates under the auspices of the Agency Chief Information Officer. It collects, organizes, provides for archiving, and disseminates NASA's STI. The NASA STI program provides access to the NASA Aeronautics and Space Database and its public interface, the NASA Technical Reports Server, thus providing one of the largest collections of aeronautical and space science STI in the world. Results are published in both non-NASA channels and by NASA in the NASA STI Report Series, which includes the following report types:

- TECHNICAL PUBLICATION. Reports of completed research or a major significant phase of research that present the results of NASA programs and include extensive data or theoretical analysis. Includes compilations of significant scientific and technical data and information deemed to be of continuing reference value. NASA counterpart of peer-reviewed formal professional papers but has less stringent limitations on manuscript length and extent of graphic presentations.

- TECHNICAL MEMORANDUM. Scientific and technical findings that are preliminary or of specialized interest, e.g., quick release reports, working papers, and bibliographies that contain minimal annotation. Does not contain extensive analysis.

- CONTRACTOR REPORT. Scientific and technical findings by NASA-sponsored contractors and grantees.
- CONFERENCE PUBLICATION. Collected papers from scientific and technical conferences, symposia, seminars, or other meetings sponsored or cosponsored by NASA.

- SPECIAL PUBLICATION. Scientific, technical, or historical information from NASA programs, projects, and missions, often concerned with subjects having substantial public interest.

- TECHNICAL TRANSLATION. Englishlanguage translations of foreign scientific and technical material pertinent to NASA's mission.

Specialized services also include creating custom thesauri, building customized databases, organizing and publishing research results.

For more information about the NASA STI program, see the following:

- Access the NASA STI program home page at http://www.sti.nasa.gov

- E-mail your question via the Internet to help@ sti.nasa.gov

- Fax your question to the NASA STI Help Desk at 443-757-5803

- Telephone the NASA STI Help Desk at 443-757-5802

- Write to: NASA Center for AeroSpace Information (CASI) 7115 Standard Drive Hanover, MD 21076-1320 


\section{Effect of Illumination Angle on the Performance of Dusted Thermal Control Surfaces in a Simulated Lunar Environment}

James R. Gaier

Glenn Research Center, Cleveland, Ohio

Prepared for the

39th International Conference on Environmental Systems (ICES)

sponsored by the Society of Automotive Engineers International

Savannah, Georgia, July 12-16, 2009

National Aeronautics and

Space Administration

Glenn Research Center

Cleveland, Ohio 44135 


\section{Acknowledgments}

This work is the result of a great deal of effort by a sizable team of dedicated professionals from many organizations. Edward A. Sechkar (Arctic Slope Research Corporation) and Frank P. Lam (TFOME) provided engineering and technical support of the LDAB facility. Scott R. Panko (Arctic Slope Research Corporation) provided both electrical engineering and test engineering support for the LDAB. Michael C. Hicks (GRC) did the thermal modeling. Don Jaworske (GRC) oversaw the fabrication of the test samples and acted as a general resource on the behavior of thermal control coatings. Funding for this work was provided by the Dust Mitigation Project and the Thermal Control Project of NASA Exploration Technology Development Program.

Trade names and trademarks are used in this report for identification only. Their usage does not constitute an official endorsement, either expressed or implied, by the National Aeronautics and Space Administration.

Level of Review: This material has been technically reviewed by technical management.

Available from

NASA Center for Aerospace Information 7115 Standard Drive

Hanover, MD 21076-1320
National Technical Information Service 5285 Port Royal Road Springfield, VA 22161 


\title{
Effect of Illumination Angle on the Performance of Dusted Thermal Control Surfaces in a Simulated Lunar Environment
}

\author{
James R. Gaier \\ National Aeronautics and Space Administration \\ Glenn Research Center \\ Cleveland, Ohio 44135
}

\begin{abstract}
JSC-1A lunar simulant has been applied to AZ93 and AgFEP thermal control surfaces on aluminum substrates in a simulated lunar environment. The temperature of these surfaces was monitored as they were heated with a solar simulator using varying angles of incidence and cooled in a $30 \mathrm{~K}$ coldbox. Thermal modeling was used to determine the solar absorptivity $(\alpha)$ and infrared emissivity $(\varepsilon)$ of the thermal control surfaces in both their clean and dusted states. It was found that even a sub-monolayer of dust can significantly raise the $\alpha$ of either type of surface. A full monolayer can increase the $\alpha / \varepsilon$ ratio by a factor of 3 to 4 over a clean surface. Little angular dependence of the $\alpha$ of pristine thermal control surfaces for both AZ93 and AgFEP was observed, at least until $30^{\circ}$ from the surface. The dusted surfaces showed the most angular dependence of $\alpha$ when the incidence angle was in the range of $25^{\circ}$ to $35^{\circ}$. Samples with a full monolayer, like those with no dust, showed little angular dependence in $\alpha$. The $\varepsilon$ of the dusted thermal control surfaces was within the spread of clean surfaces, with the exception of high dust coverage, where a small increase was observed at shallow angles.
\end{abstract}

\section{Introduction}

National Space Policy calls for NASA to return humans to the Moon by 2020. Largely due to the lack of an appreciable atmosphere, the lunar surface environment is hostile. In addition to being at ultrahigh vacuum $\left(10^{-12}\right.$ Torr during the day at $10^{-14}$ Torr during the night), there are thermal extremes (100 to $400 \mathrm{~K}$ ), unshielded solar electromagnetic and particle radiation, cosmic radiation, and an unceasing bombardment of meteoroids. But of all of the environmental threats on the Moon, the one singled out by Apollo astronauts as being the most worrisome is lunar dust. They were particularly surprised by how much the thermal control surfaces were affected. For example, even though they were equipped with dust covers and were brushed off at regular intervals, the batteries for the lunar roving vehicle ran hotter than anticipated, and in fact hotter than their rated operating temperature for part of the time (Ref. 1). Since the new lunar architecture calls for the next generation of surface systems to operate on the lunar surface for years rather than the days required of Apollo systems, a joint task has been developed by the Dust Mitigation Project and the Advanced Thermal Control Project to quantify the effects of lunar dust on thermal control surfaces and to develop mitigation strategies.

The current lunar exploration architecture calls for exploring the lunar poles. Since the radiators will likely be facing up into space to radiate to the lowest temperature, solar radiation will be striking these surfaces at low angles. This study sought to determine the effect of solar incidence angle on the absorptivity $(\alpha)$ of pristine thermal control surfaces. The second objective was to continue the investigation into the effect of dust on the $\alpha$ of the thermal control surfaces. The third objective was to determine the effect of dust on the angular dependence of $\alpha$ of these surfaces.

\section{Methods and Materials}

This study utilized a white thermal control paint (AZ93) and a second surface mirror (Ag coated FEP Teflon, Dupont) as the thermal control surfaces. The thermal control surfaces were applied to $2.54 \mathrm{~cm}(1 \mathrm{in}$.) diameter aluminum substrates. The AZ-93 paint was applied by AZ Technology (Huntsville, Alabama). The AgFEP appliqués were fabricated by Sheldahl (Northfield, Minnesota) from $12.7 \mu \mathrm{m}$ (5 mil) thick FEP Teflon which was coated with a few tens of nm of silver and a few tens of $\mathrm{nm}$ of Inconel as a sealing layer to prevent oxidation. They were hand-applied to the substrates using a film adhesive.

The tests were carried out using the NASA Lunar Dust Adhesion Bell jar (LDAB). The lunar simulation facility enables the simulated lunar dust to be heated, dried, plasmacleaned, chemically reduced, and sieved onto samples in situ. It operates at a pressure of $10^{-5} \mathrm{~Pa}\left(10^{-8}\right.$ Torr). The sample, pristine or dusted, can be heated using a 20 -Sun xenon arc lamp solar simulator, and radiatively cooled in a $30 \mathrm{~K}$ coldbox. Details of the LDAB are available elsewhere (Ref. 2). One AZ-93 coated sample and one AgFEP sample were exposed during each test in a single sample holder. Figure 1 shows two samples mounted in the LDAB sample holder.

Approximately $15 \mathrm{~g}$ of JSC-1AF lunar simulant was placed in the activation bowl of the LDAB where it was stirred as a vacuum was pulled down to about $13 \mathrm{~Pa}$ (100 mTorr). At this pressure it was exposed to a radio frequency air plasma for $1 \mathrm{hr}$, with intermittent stirring, to remove organic contaminants. The chamber was then pumped down to about $10^{-4} \mathrm{~Pa}\left(10^{-6}\right.$ Torr $)$ and the simulant was heated at least $16 \mathrm{hr}$ to at least $200{ }^{\circ} \mathrm{C}$, with stirring, to remove water. After cooling to room temperature, the chamber was backfilled with a 
5 percent $\mathrm{H}_{2}$ in $\mathrm{He}$ gas to a pressure of $13 \mathrm{~Pa}$ and the dust was exposed to a radio frequency plasma for $1 \mathrm{hr}$, with intermittent stirring, to chemically reduce and to add hydrogen to the dust particle surfaces. This was to mimic the effects of solar wind. The $\mathrm{H}_{2}-\mathrm{He}$ mixture was pumped out and the pressure again dropped to $10^{-4} \mathrm{~Pa}$. Then a recirculating He refrigerator was used to cool a cold box within the chamber to about $30 \mathrm{~K}$. The resulting condensation of gases onto the surface of the cold box lowered the pressure in the chamber to about $10^{-5} \mathrm{~Pa}$. This was the level of vacuum under which most of the testing was carried out. The dust was transferred from the activation bowl to a 3 in. standard, $38 \mu \mathrm{m}$ stainless steel sieve for application to the samples.

One of the samples was positioned under a 20-Sun Xe arc lamp (Luxtel), and tilted to the desired incidence angle using a bubble-level type angle indicator. Incidence angles of $90^{\circ}$, $45^{\circ}, 30^{\circ}$, and $10^{\circ}$ were used. After the temperature recording software was started, the arc lamp was ignited. The sample was exposed for $800 \mathrm{sec}$, or until the temperature approached $200{ }^{\circ} \mathrm{C}$, whichever came first. Then the second sample was positioned under the lamp and exposed for a similar duration. Then the lamp was extinguished, the angle returned to $90^{\circ}$, and the sample holder was translated into the cold box, which is lined with an absorbing material (Vel-Black) and maintained at about $30 \mathrm{~K}$ with a recycling helium refrigerator. The samples were allowed to cool for at least $20 \mathrm{~min}$, or until the temperature of both samples was below $15^{\circ} \mathrm{C}$, whichever took the longest. The sample was then pulled out of the cold box, though still in the vacuum chamber, and allowed to come to near equilibrium temperature before the next test was started.

After heating and cooling data had been collected at all four angles, the sample was positioned under a $25 \mu \mathrm{m}$ sieve filled

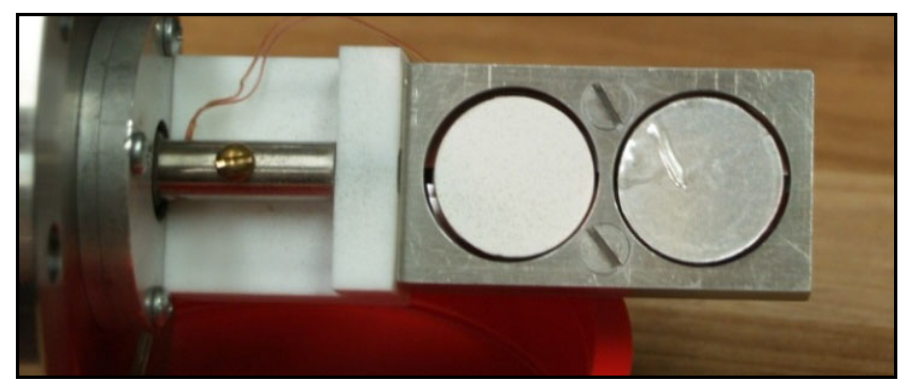

Figure 1.-Aluminum substrate coated with AZ-93 (left) and Ag/FEP (right) thermal control surfaces. The thin brown wires in the photo are two thermocouples, one connected to each sample.

with activated dust. Dust was sieved onto the sample at an angle of $90^{\circ}$ in all cases. The sample was then translated under the Xe arc lamp, and heated at incidence angles of $90^{\circ}, 45^{\circ}$, $30^{\circ}$, and $10^{\circ}$, and cooled using the procedure described above for the pristine samples.

In some cases a Kimball Physics (Wilton, NH) model FRA2X1-2 electron flood gun sprayed electrons onto the dust as it dropped from the sieve onto the samples. The electron energy was set at $1000 \mathrm{~V}$, and the emission current was about $200 \mu \mathrm{A}$. It should be noted that this was a rather narrow beam, so only some fraction of the falling dust was directly exposed to the electrons.

Fractional dust coverage was determined from images obtained with an optical microscope at $100 \times$ using image analysis software and a rigorous statistical procedure. The process has been described in detail elsewhere (Ref. 3). The mean of 50 measurements was calculated for each sample, as was the 95 percent confidence interval.

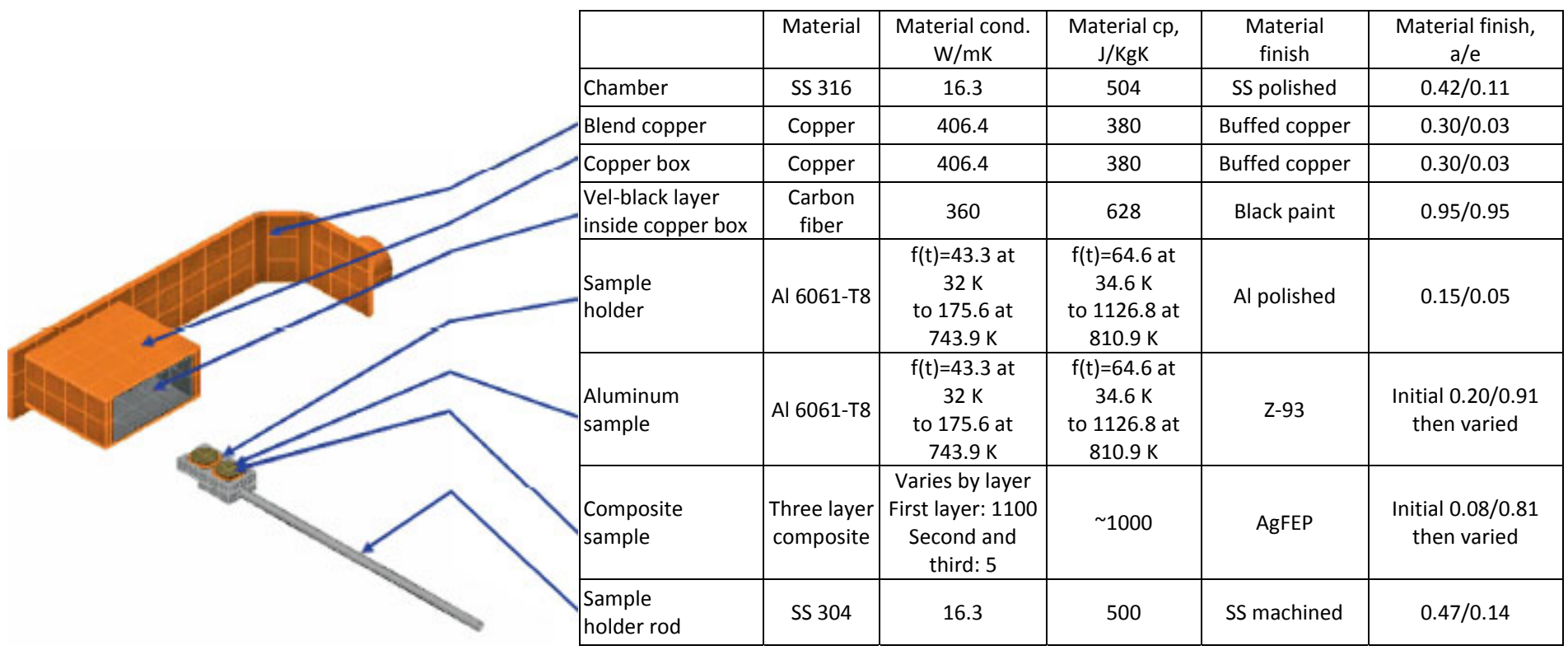

Figure 2.-Picture of the thermal model and parameters used in its construction. 
The thermal modeling was done using Thermal Desktop (Cullimore \& Ring Technologies), a PC based design environment for generating thermal models of electronics and vehicles. Thermal Desktop incorporates both parameter based finite difference surfaces with finite elements and CAD technology to model thermal problems. Thermal Desktop develops the capacitance and conductance network for input to SINDA/Fluint which is a comprehensive finite-difference, lumped parameter (circuit or network analogy) tool for heat transfer design analysis and fluid flow analysis in complex systems. Thermal Desktop 5.1 Patch 3 was used to generate the thermal model, which consists of 743 nodes and 1840 linear conductors. A visualization of the model and the material parameters used in it are shown in Figure 2.

Because there were concerns that the intensity of the Xe arc lamp might be changing over time, it was calibrated for each sample assuming that the absorptivity $(\alpha)$ of the AZ-93 sample at $90^{\circ}$ was the same as the literature value $(0.200)$. The emissivity $(\varepsilon)$ was determined from the measured cooling curve. The lamp intensity was then varied until the calculated heating curve fit the experimental data within 0.5 percent. That lamp intensity was used for the rest of the pristine and dusted heating curves for that sample, and $\alpha$ was varied until the model matched the heating curve data to within 0.5 percent. This process was repeated for each of the AZ93 samples. This same lamp intensity was also used for the corresponding AgFEP analysis. The data were collected for both types of surfaces at the same time and the AZ93 data was considered more reliable because of the unknown effects of the light on the $90^{\circ} \mathrm{AgFEP}$ being reflected back up onto the lamp.

\section{Results and Discussion}

\section{$90^{\circ}$ Test Results}

The data collected at $90^{\circ}$ is in every way equivalent to the thermal control surfaces on data taken in a previous study (FY08) (Ref. 4). Figure 3 compares the optical constants calculated in this study (FY09) with those calculated previously and the literature values. Since the $\alpha$ of the $90^{\circ}$ AZ93 samples was constrained to be 0.20 , and the experimentally determined $\varepsilon$ was found to be the same in three of the four AZ93 samples, three of those points are superimposed in the plot at $\varepsilon=0.89$ and $\alpha=0.20$. This is not the case for the AZ93 samples from FY08 where the $\alpha$ from the first sample was used to set the lamp intensity, and the $\alpha$ was allowed to vary for the other three. The $\alpha$ for the AgFEP in the FY09 data set was very consistent, $0.104 \pm 0.001$, but somewhat higher than the FY08 sample $\alpha$ of $0.074 \pm 0.002$.

The average $\varepsilon$ of the AZ93 was found to be 0.895 , close to the literature values of 0.90 to 0.92 . The high precision in the value of $\varepsilon$ compared to the FY08 study draws from more

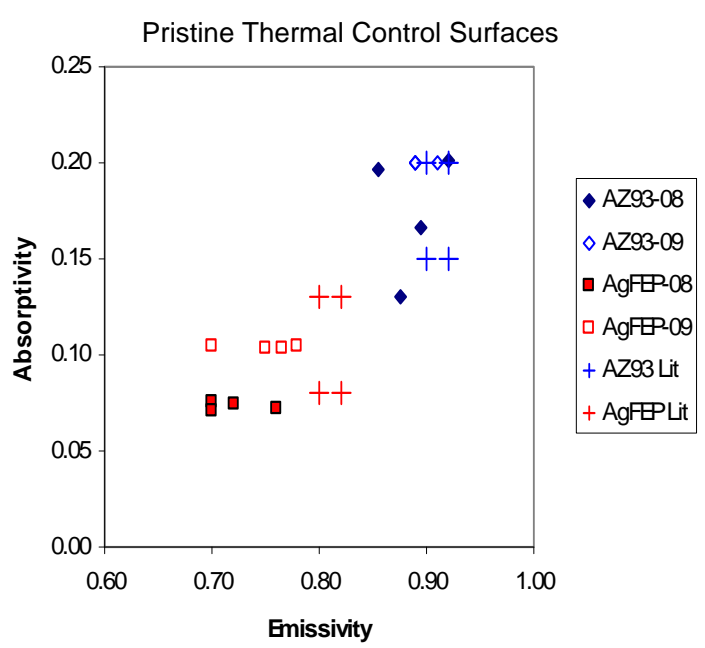

Figure 3.-Plot of the $\alpha$ and $\varepsilon$ calculated for the eight pristine $90^{\circ}$ samples (open), the eight calculated from the 2008 study (filled), and the literature values (+) for AZ93 and AgFEP.

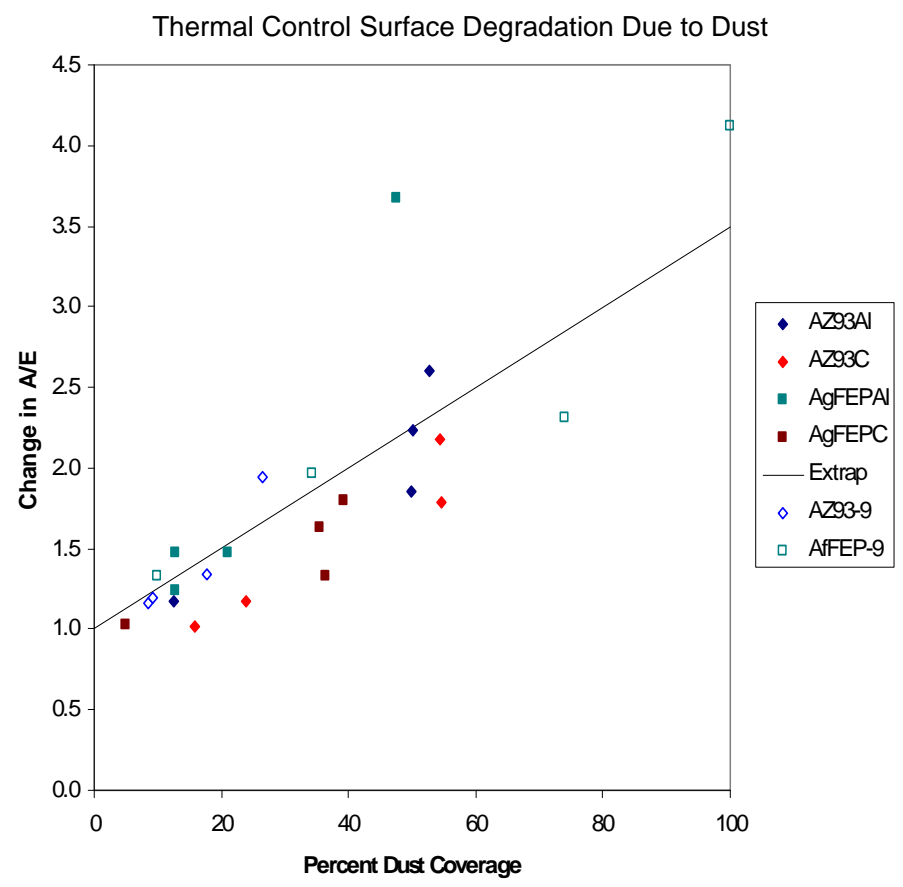

Figure 4.-The relationship between $\alpha / \varepsilon$ as a function of percent JSC-1A lunar simulant dust coverage for all of the $90^{\circ}$ data collected during FY08 (filled) and this study (open). A least squares line through the data indicates a monolayer of dust coverage increases the $\alpha / \varepsilon$ by a factor of 3.5 .

consistent cooling curves. It is tempting to attribute this to the new sample holder arrangement that holds the sample in a more reproducible position within the cold box, however, as can be seen in Figure 3 the $\varepsilon$ for the AgFEP had essentially the same spread in the FY09 data as in the FY08 data. 
The results from the dusted $90^{\circ}$ samples were also consistent with the FY08 data. Although direct comparisons were not available because the samples cannot be dusted reproducibly, the trends appear to be the same. This is evident in Figure 4 which shows the $\alpha / \varepsilon$ ratio as a function of percent dust coverage. The FY09 data fall along nearly the same line as the FY08 data. The least squares line indicates that a thermal control surface covered with a monolayer of JSC-1A lunar simulant dust has a $\alpha / \varepsilon$ ratio 3.5 times greater than a clean surface. If the apparently anomalous point at 48 percent coverage and $\alpha / \varepsilon$ of 3.7 is deleted the intercept drops to 3.3 . But the empirical $\alpha / \varepsilon$ measured for the completely dust covered AgFEP-903 sample was 4.1. It is concluded that the value of $\alpha / \varepsilon$ for a complete monolayer of dust is increased by a factor of 3-4 over pristine surfaces, and appears to be independent of thermal control surface type or substrate.

\section{Angular Dependence of $\alpha$ For Pristine Surfaces}

Figure 5 shows the relative $\alpha\left(\alpha / \alpha_{90^{\circ}}\right)$ of three pristine AZ93 surfaces as a function of incidence angle. (No pristine AZ93902 angular data were available.) Recall that the $90^{\circ}$ case was constrained to have the same $\alpha, 0.20$. What is probably the most striking characteristic about these data is that the spread in the data increased as the angle becomes more shallow. This may, at least in part, be an artifact of the sample holder. The sample holder was not designed to hold the samples at high angle. In fact, a geometric analysis shows that there was enough play in the way that the samples were held by the Kapton (Dupont) clamshell that there could be a deviation of as much as $6^{\circ}$ from the set angle for AZ93-901, and $4^{\circ}$ for AZ93-903 and AZ93-904. With the $\sin \theta$ dependency this deviation has much more impact on the $\alpha$ calculated when the modeled $\theta=10^{\circ}$ than when the modeled $\theta=90^{\circ}$. So while the AZ93-903 and AZ93-904 samples show essentially no angular dependence of $\alpha$, the AZ93-901 sample shows a marked dependence, with the $\alpha$ at $10^{\circ}$ varying by 35 percent from that of the $90^{\circ}$. Modifications have been made in the sample and sample holder to eliminate this source of error in the future, and more data will be taken to clarify this issue, but the tentative conclusion is that pristine AZ93 has no appreciable angular dependence in $\alpha$ at angles as shallow as $30^{\circ}$. The spread in the data at $10^{\circ}$ leaves any conclusions about it in doubt. But these data are consistent with the finding of Jaworske who measured the reflectance of Z-93-P thermal control paint as a function of angle (Ref. 5). He found only very small changes in the reflectance as a function of angle down to $30^{\circ}$ for light in the 3 to $40 \mu \mathrm{m}$ range. However, at angles of $10^{\circ}$ to $20^{\circ}$ there was significant increases in reflectance. Since light impinging on an opaque surface must either be reflected of absorbed, this would imply little change in $\alpha$ over that range as well.

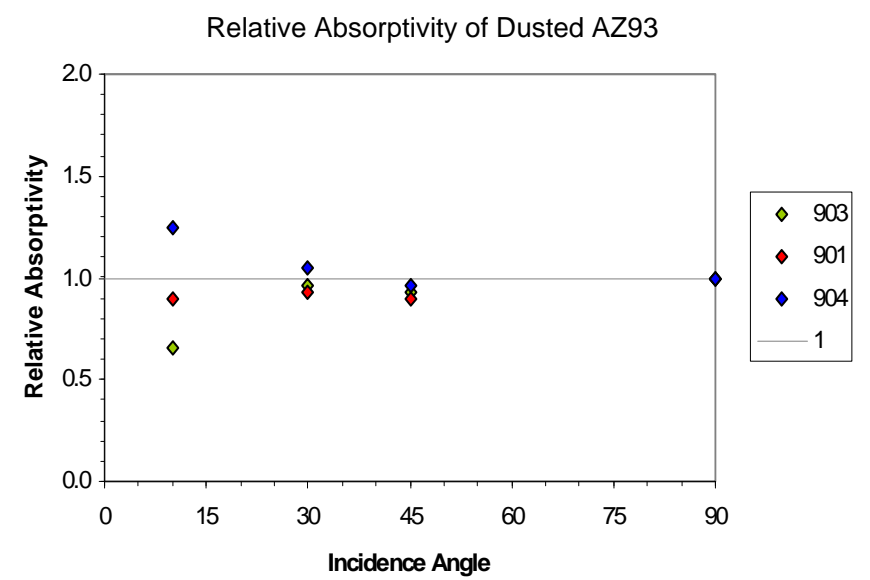

Figure 5.-The $\alpha / \alpha_{90}$ for pristine AZ-93 as a function of incidence angle.

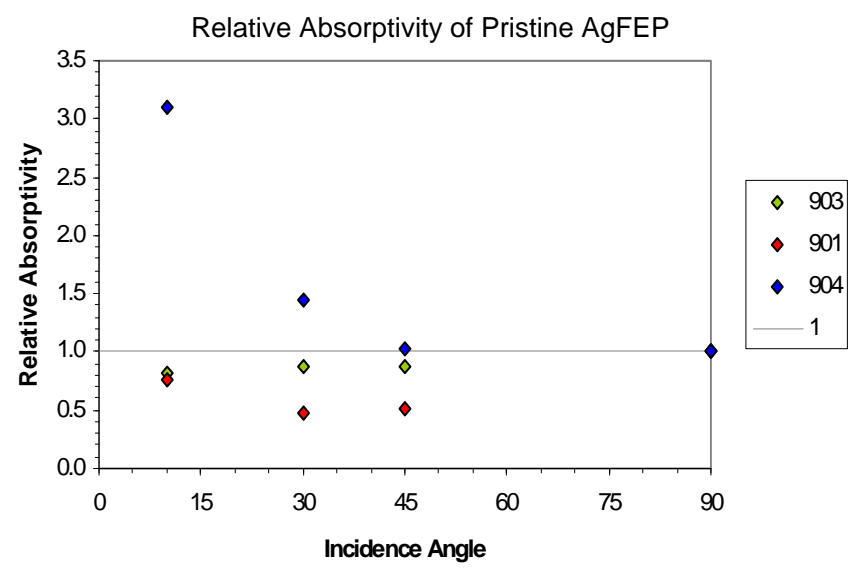

Figure 6.-The $\alpha / \alpha_{90}$ for pristine AgFEP as a function of incidence angle.

The $\alpha$ as a function of incidence angle for pristine AgFEP is shown in Figure 6. Only $90^{\circ}$ data are available for the AgFEP902 samples. Unlike the AZ93 samples, the AgFEP-903 and AgFEP-904 samples utilized the new sample substrate and holder that maintains the angle very well. So for those two the increase in spread in the data as the angle becomes more shallow is not due to angular error. The relative $\alpha$ for the AgFEP-904 climbs markedly while that for AgFEP-903 actually dips. More trials will be required before conclusions can be drawn.

\section{Angular Dependence of $\alpha$ For Dusted Surfaces}

Figure 7 shows the relative $\alpha$ of AZ93 surfaces dusted to four different levels as a function of incidence angle. It appears that at coverage as high as 26 percent there is no 
significant angular dependence until the angle becomes very shallow $\left(10^{\circ}\right)$. At these shallow angles the relative $\alpha$ increases as the dust coverage decreases. Though as noted above, this may be at least in part, an artifact of the sample holder.

The corresponding plot of the relative $\alpha$ of AgFEP surfaces dusted to four different levels as a function of incidence angle is shown in Figure 8. Note that the levels of dust coverage are higher than in the AZ-93 case, and in fact the AgFEP-903 samples were completely covered with dust. The AgFEP-901 samples were 74 percent covered, more than twice the dust on the dustiest AZ-93 sample. This plot indicates that if the AgFEP is totally, or even mostly covered by dust, there is no angular dependence to angles as shallow as $10^{\circ}$. But, like the AZ93 case, if the dust coverage is in the 10 to 34 percent range, there is an increase in the relative $\alpha$ at the very shallow angles.

\section{Emissivity of Pristine and Dusted Samples}

It has been the conventional wisdom that since the lunar regolith is so dark that dust on a thermal control surface will have no appreciable effect on the $\varepsilon$. The FY08 data seemed to call that into question, with $\varepsilon$ of the AZ93 samples apparently decreasing with dust coverage and the $\varepsilon$ of AgFEP increasing with dust coverage, given the data on both aluminum and composite substrates. The FY08 data have been combined with the $90^{\circ}$ FY09 data in Figure 9. The combined data calls for a reconsideration of the original contention. Although the $\varepsilon$ of the most heavily dusted AZ93 samples tend to fall below the range of undusted, and the most heavily dusted AgFEP samples tend to fall above the range of the undusted, most of the $\varepsilon$ values of the dusted samples fall within the range of the pristine samples. This will only be resolved by taking additional data. But from a technology development perspective, the effect is not pronounced.

\section{Conclusions}

There are four major conclusions that can be drawn from this study. The first is confirmation that even a sub-monolayer of simulated lunar dust can significantly degrade the performance of both white paint and second-surface mirror type radiators under simulated lunar conditions. If anything, the results of this study point to a slightly higher degradation in the $\alpha / \varepsilon$ value, increasing to a factor of 3 to 4 for the case of full monolayer coverage.

The second conclusion is that there is little angular dependence of the $\alpha$ of pristine thermal control surfaces in both AZ93 and AgFEP. Although there may be an effect at angles as shallow as $10^{\circ}$, the experimental error in the angle

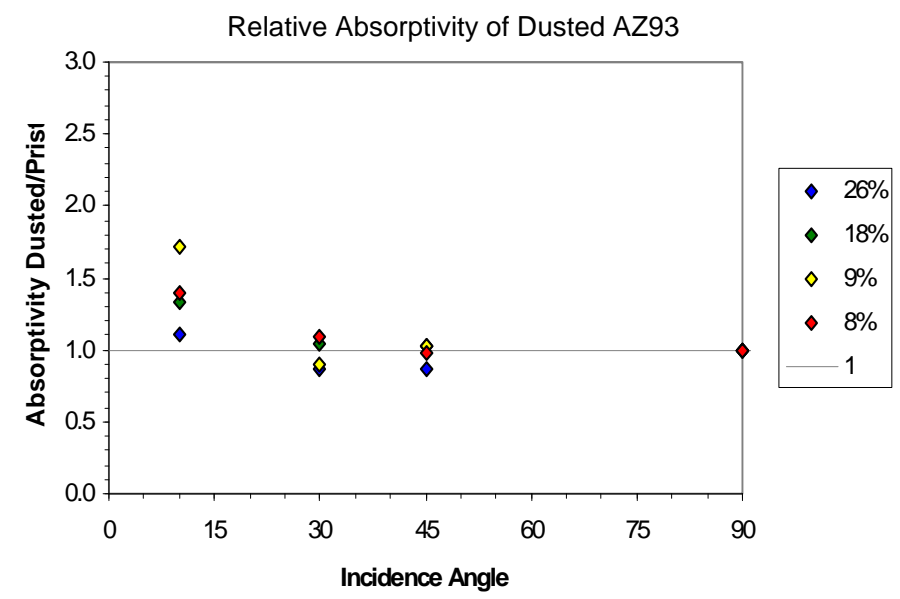

Figure 7.-The $\alpha / \alpha_{90}$ for AZ-93 dusted to four different levels as a function of incidence angle.

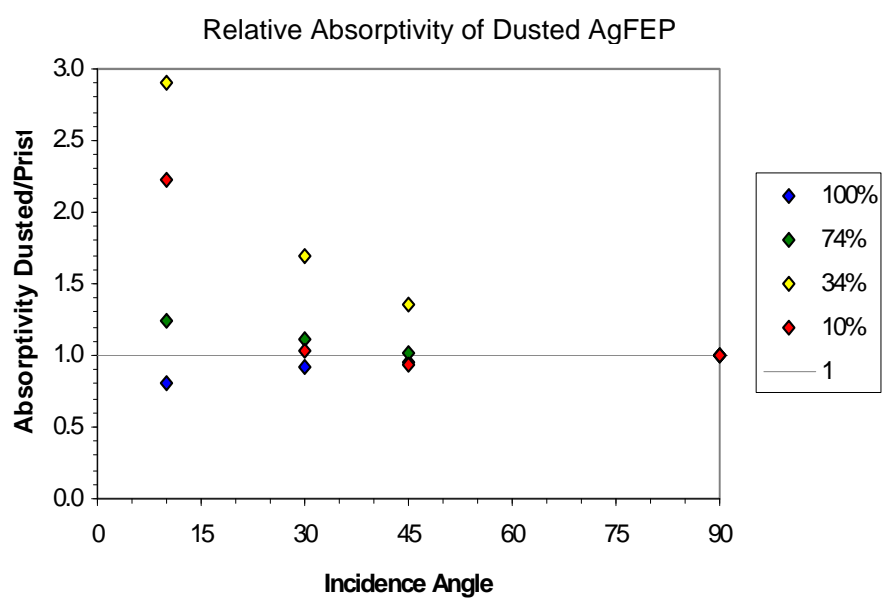

Figure 8.-The $\alpha / \alpha_{90}$ for AgFEP dusted to four different levels as a function of incidence angle.

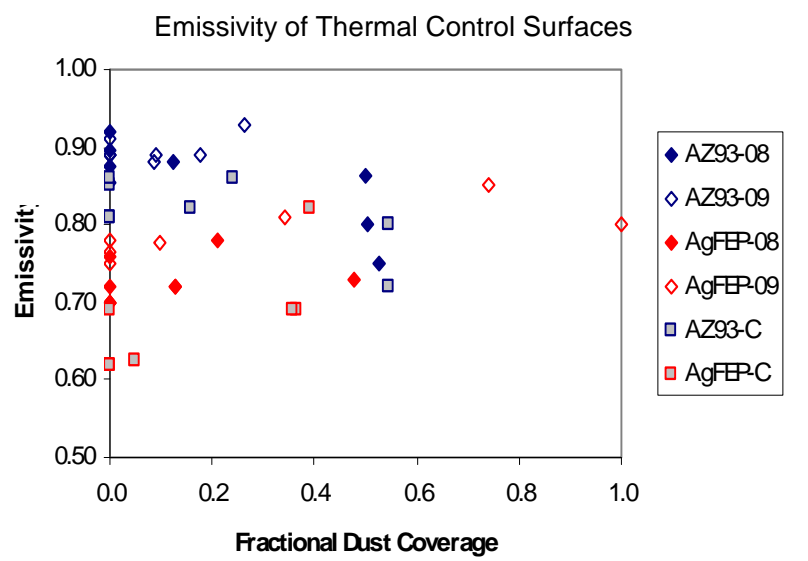

Figure 9.-Plot of $\varepsilon$ as a function of fractional dust coverage for all of the thermal control samples characterized to date. 
measurement may be as large as $6^{\circ}$, and this can perhaps explain the increasing spread in the data with shallower angle. The sample holder has been redesigned to improve the precision and it is hoped that this issue will be resolved by future tests.

The third conclusion, which is tentative, is that there is little angular dependence of sub-monolayer coatings of dust, particularly at very low and very high dust coverage. In the 25 to 35 percent coverage range the $\alpha$ may be enhanced at shallow angles, perhaps by as much as a factor of 3 . More precise angle control and additional data are required to confirm this.

The fourth conclusion is actually a backing away from the idea that at high loading the $\varepsilon$ of the thermal control surfaces is significantly affected. More data will be required to confirm whether this effect is real.

\section{References}

1. J.R. Gaier and D.A. Jaworske, "Lunar Dust on Heat Rejection System Surfaces: Problems and Prospects," STAIF07, Paper 26, and NASA/TM-2007-214814.

2. J.R. Gaier and E.A. Sechkar, "Lunar Simulation in the Lunar Dust Adhesion Bell Jar," Presented at the $45^{\text {th }}$ AIAA Technical Conference as AIAA-2007-0963, and NASA/TM-2007214704.

3. J.R. Gaier, J. Siamidis, and E.M.G. Larkin, NASA/CP-2008214164, 25th Space Simulation Conference (2008).

4. J.R. Gaier et al., "The Effect of Simulated Lunar Dust on the Absorptivity, Emissivity, and Operating Temperature of AZ-93 and Ag/FEP Thermal Control Surfaces," NASA/TM-2008215492.

5. D.A. Jaworske, "Optical and Calorimetric Evaluation of Z-93-P and Other Thermal Control Coatings, Thin Solid Films," (1996) pp. $278-282$. 


\begin{tabular}{|c|c|c|}
\hline \multicolumn{2}{|c|}{ REPORT DOCUMENTATION PAGE } & $\begin{array}{c}\text { Form Approved } \\
\text { OMB No. 0704-0188 }\end{array}$ \\
\hline \multicolumn{3}{|c|}{ 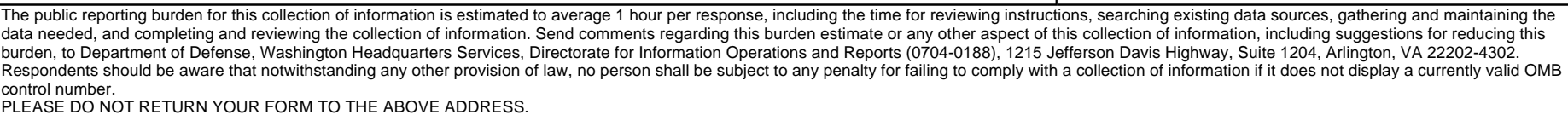 } \\
\hline $\begin{array}{l}\text { 1. REPORT DATE (DD-MM-YYYY) } \\
01-10-2009\end{array}$ & $\begin{array}{l}\text { 2. REPORT TYPE } \\
\text { Technical Memorandum }\end{array}$ & 3. DATES COVERED (From - To) \\
\hline \multirow{3}{*}{\multicolumn{2}{|c|}{$\begin{array}{l}\text { 4. TITLE AND SUBTITLE } \\
\text { Effect of Illumination Angle on the Performance of Dusted Therma } \\
\text { Simulated Lunar Environment }\end{array}$}} & 5a. CONTRACT NUMBER \\
\hline & & 5b. GRANT NUMBER \\
\hline & & 5c. PROGRAM ELEMENT NUMBER \\
\hline \multirow{3}{*}{\multicolumn{2}{|c|}{$\begin{array}{l}\text { 6. AUTHOR(S) } \\
\text { Gaier, James, R. }\end{array}$}} & 5d. PROJECT NUMBER \\
\hline & & 5e. TASK NUMBER \\
\hline & & $\begin{array}{l}\text { 5f. WORK UNIT NUMBER } \\
\text { WBS 119103.04.05.04 }\end{array}$ \\
\hline \multicolumn{2}{|c|}{$\begin{array}{l}\text { 7. PERFORMING ORGANIZATION NAME(S) AND ADDRESS(ES) } \\
\text { National Aeronautics and Space Administration } \\
\text { John H. Glenn Research Center at Lewis Field } \\
\text { Cleveland, Ohio 44135-3191 }\end{array}$} & $\begin{array}{l}\text { 8. PERFORMING ORGANIZATION } \\
\text { REPORT NUMBER } \\
\text { E-16959 }\end{array}$ \\
\hline \multirow{2}{*}{\multicolumn{2}{|c|}{$\begin{array}{l}\text { 9. SPONSORING/MONITORING AGENCY NAME(S) AND ADDRESS(ES) } \\
\text { National Aeronautics and Space Administration } \\
\text { Washington, DC 20546-0001 }\end{array}$}} & $\begin{array}{l}\text { 10. SPONSORING/MONITOR'S } \\
\text { ACRONYM(S) } \\
\text { NASA }\end{array}$ \\
\hline & & $\begin{array}{l}\text { 11. SPONSORING/MONITORING } \\
\text { REPORT NUMBER } \\
\text { NASA/TM-2009-215647 }\end{array}$ \\
\hline \multicolumn{3}{|c|}{$\begin{array}{l}\text { 12. DISTRIBUTIONIAVAILABILITY STATEMENT } \\
\text { Unclassified-Unlimited } \\
\text { Subject Category: } 91 \\
\text { Available electronically at http://gltrs.grc.nasa.gov } \\
\text { This publication is available from the NASA Center for AeroSpace Information, 443-757-5802 }\end{array}$} \\
\hline
\end{tabular}

\section{SUPPLEMENTARY NOTES}

\section{ABSTRACT}

JSC-1A lunar simulant has been applied to AZ93 and AgFEP thermal control surfaces on aluminum substrates in a simulated lunar environment. The temperature of these surfaces was monitored as they were heated with a solar simulator using varying angles of incidence and cooled in a $30 \mathrm{~K}$ coldbox. Thermal modeling was used to determine the solar absorptivity (a) and infrared emissivity (e) of the thermal control surfaces in both their clean and dusted states. It was found that even a sub-monolayer of dust can significantly raise the a of either type of surface. A full monolayer can increase the a/e ratio by a factor of 3 to 4 over a clean surface. Little angular dependence of the a of pristine thermal control surfaces for both AZ93 and AgFEP was observed, at least until $30^{\circ}$ from the surface. The dusted surfaces showed the most angular dependence of a when the incidence angle was in the range of $25^{\circ}$ to $35^{\circ}$. Samples with a full monolayer, like those with no dust, showed little angular dependence in a. The e of the dusted thermal control surfaces was within the spread of clean surfaces, with the exception of high dust coverage, where a small increase was observed at shallow angles.

\section{SUBJECT TERMS}

Lunar soil; Lunar dust; Thermal control

\begin{tabular}{|c|c|c|c|c|c|}
\hline \multicolumn{3}{|c|}{ 16. SECURITY CLASSIFICATION OF: } & \multirow{2}{*}{$\begin{array}{l}\text { 17. LIMITATION OF } \\
\text { ABSTRACT } \\
\text { UU }\end{array}$} & \multirow{2}{*}{$\begin{array}{l}\text { 18. NUMBER } \\
\text { OF } \\
\text { PAGES } \\
11\end{array}$} & \multirow{2}{*}{$\begin{array}{l}\text { 19a. NAME OF RESPONSIBLE PERSON } \\
\text { STI Help Desk (email:help@sti.nasa.gov) } \\
\text { 19b. TELEPHONE NUMBER (include area code) } \\
\text { 443-757-5802 }\end{array}$} \\
\hline $\begin{array}{l}\text { a. REPORT } \\
U\end{array}$ & $\begin{array}{l}\text { b. ABSTRACT } \\
U\end{array}$ & $\begin{array}{l}\text { c. THIS } \\
\text { PAGE } \\
\text { U }\end{array}$ & & & \\
\hline
\end{tabular}



